\title{
GATA3 as an Adjunct Prognostic Factor in Breast Cancer Patients with Less Aggressive Disease: A Study with a Review of the Literature
}

\author{
Patrizia Querzoli ${ }^{1}$, Massimo Pedriali ${ }^{1}$ (D), Rosa Rinaldi ${ }^{2}$ (D), Paola Secchiero ${ }^{3}$, Paolo Giorgi Rossi ${ }^{4}$ (D) \\ and Elisabetta Kuhn 5,6,*
}

check for updates

Citation: Querzoli, P.; Pedriali, M.; Rinaldi, R.; Secchiero, P.; Rossi, P.G.; Kuhn, E. GATA3 as an Adjunct Prognostic Factor in Breast Cancer Patients with Less Aggressive Disease: A Study with a Review of the Literature. Diagnostics 2021, 11 , 604. https://doi.org/10.3390/ diagnostics11040604

Academic Editors: Paula A. Oliveira and Dario de Biase

Received: 2 February 2021

Accepted: 23 March 2021

Published: 28 March 2021

Publisher's Note: MDPI stays neutral with regard to jurisdictional claims in published maps and institutional affiliations.

Copyright: (c) 2021 by the authors. Licensee MDPI, Basel, Switzerland. This article is an open access article distributed under the terms and conditions of the Creative Commons Attribution (CC BY) license (https:/ / creativecommons.org/licenses/by/ $4.0 /)$.
1 Section of Anatomic Pathology, Department of Morphology, Surgery and Experimental Medicine, University of Ferrara, 44124 Ferrara, Italy; patrizia.querzoli@unife.it (P.Q.); mpedriali@gmail.com (M.P.)

2 Section of Anatomic Pathology, ASST Mantova, Ospedale Carlo Poma, 46100 Mantova, Italy; rosa.rinaldi@asst-mantova.it

3 Surgery and Experimental Medicine and Interdepartmental Center of Technology of Advanced Therapies (LTTA), Department of Morphology, University of Ferrara, 44121 Ferrara, Italy; paola.secchiero@unife.it

4 Epidemiology Unit, Azienda Unità Sanitaria Locale-IRCCS di Reggio Emilia, 42122 Reggio Emilia, Italy; paolo.giorgirossi@ausl.re.it

5 Division of Pathology, Fondazione IRCCS Ca' Granda, Ospedale Maggiore Policlinico, 20122 Milano, Italy

6 Department of Biomedical, Surgical, and Dental Sciences, University of Milan, 20122 Milano, Italy

* Correspondence: elisabetta.kuhn@unimi.it; Tel.: +39-02-5032-0564; Fax: +39-02-5503-2860

Abstract: Background: GATA binding protein 3 (GATA3) expression is positively correlated with estrogen receptor (ER) expression, but its prognostic value as an independent factor remains unclear. Thus, we undertook the current study to evaluate the expression of GATA3 and its prognostic value in a large series of breast carcinomas (BCs) with long-term follow-up. Methods: A total of 702 consecutive primary invasive BCs resected between 1989 and 1993 in our institution were arranged in tissue microarrays, immunostained for ER, progesterone receptor (PR), ki-67, HER2, p53, and GATA3, and scored. Clinico-pathological data were retrospectively collected. Results: GATA3 was evaluable in 608 (87\%) of the 702 cases; it was positive in $413(68 \%)$ cases and negative in $195(32 \%)$ cases. GATA3 positivity was significantly associated with lower grade $(p<0.0001)$, size $(p=0.0463)$, stage $(p=0.0049), \mathrm{ER}+(p<0.0001), \mathrm{PR}+(p<0.0001), \mathrm{HER} 2-(p=0.0175)$, and p53 wild-type pattern $(p<0.0001)$. The median follow-up was 183 months, GATA3 positivity was associated with better overall survival (HR 0.70, $p=0.001$ ), and its prognostic value was retained in a multivariate analysis. The association with better overall survival was stronger in patients with grade 1-2, pT1-2, pN0, stage I-II, ER+, PR+, ki-67 < 20\%, HER2-, a wild-type p53 immunohistochemical pattern, and in luminal B BC. Conclusions: Our findings indicate that GATA3 is a positive prognostic marker in $B C$ patients, especially in patients with biologically less aggressive BC. Incorporating GATA3 immunohistochemistry into routine practice could help further stratify BC patients for their risk.

Keywords: breast cancer; breast; GATA3; prognosis; prognostic factor; biomarker

\section{Introduction}

Medical oncologists treating breast cancer $(\mathrm{BC})$ patients rely on well-known prognostic and predictive factors in order to provide the most appropriate and individualized clinical management. The main clinico-pathological features of BC with a recognized prognostic value include tumor size, axillary lymph node status, and histological grade, while hormone receptor and HER2 statuses effectively predict the response to hormonal or anti-HER2 target therapies, respectively [1-3]. More recently, multigene tests have been proposed to predict the prognosis and response to chemotherapy, and have been entered in several recommendations $[4,5]$, but their high costs reduce the opportunity for routine 
use [4]. However, individual outcome differences cannot be fully explained only by single factors by these multigene tests. Therefore, additional and affordable prognostic factors are still needed.

GATA binding protein 3 (GATA3), a member of the GATA family, plays a pivotal role in the tissue determination of many organs, in particular T cells and the mammary gland [6-8]. Specifically, GATA3 is critical for the luminal differentiation of breast epithelial cells and in the morphogenesis of the mammary gland [6,8]. Coherently, GATA3 expression in human BCs is positively associated with estrogen receptor (ER) expression, and is required for cell cycle progression of ER-positive cell lines and coregulated with ER. On the other hand, it has been found that, in ER-negative cell lines, GATA3 interacts with wild-type BRCA1, but it is incapable of binding to mutant BRCA1 [9]. This finding is important, since the disruption of the BRCA1/GATA3 interaction could be the biochemical mechanism underlining the aggressive behavior of basal-like BC [9]. Moreover, GATA3 lacks leads to a chemo-resistant and mesenchymal phenotype of BC $[10,11]$. Functionally, GATA3 expression in BC cell lines and murine models reduces the tumor-initiating ability, the epithelial to mesenchymal transition, and the metastatic potential [12].

The importance of GATA3 in breast biology is further emphasized by the fact that GATA3 is one of the few recurrently mutated genes in BC, occurring in $12-16 \%$ of $\mathrm{BCs}$ across all different subtypes $[13,14]$. Interestingly, specific GATA3 mutations have been identified in causing a congenital developmental disorder characterized by hypoparathyroidism, sensorineural deafness, and renal insufficiency (so-called HDR syndrome). Similarly to HDR syndrome mutations, most of the GATA3 somatic mutations found in BC hit the Cterminal zinc finger region, revealing the key role this region has in the normal functionality of the protein $[13,14]$.

Many studies have investigated GATA3 as a prognostic marker in BC patients, with conflicting findings. On one hand, GATA3 mutations and gene expression have been associated with better prognosis and improved survival [15-17]. On the other hand, GATA3 expression closely parallels ER expression in BCs, so that it does not seem to be a prognostic factor independent of ER status [18]. Hence, whether or not GATA3 carries independent prognostic information in BC patients remains an open question. As a consequence, we undertook the current study to evaluate the expression of GATA3 by immunohistochemistry (IHC) in a large consecutive series of invasive BCs with longterm follow-up and to correlate that with clinico-pathological characteristics, biological markers, p53 status, and clinical outcome, in order to better clarify whether GATA3 carries independent prognostic information.

\section{Materials and Methods}

\subsection{Patients}

Eligible patients were all female BC patients diagnosed and surgically treated from January 1989 to December 1993 at the surgical units of the S. Anna University Hospital of Ferrara or at other hospitals in the Ferrara province. Exclusion criteria were not having available tumor formalin-fixed and paraffin-embedded blocks, undergoing neoadjuvant treatment, and having systemic metastasis at diagnosis. A total of 702 consecutive primary invasive BCs were retrieved from the pathological files of our institution and included in this study.

All patients were treated according to our institution guidelines before the introduction of the current therapy based on BC molecular intrinsic subtypes. After the first-line treatment was completed, patients were re-examined twice a year for the first five years, then annually for the following years. Clinical baseline data, including patient age, tumor histology, pathologic stage, grading, and follow-up data (last follow-up time, date of death, and cause of death), were retrospectively collected from the pathology files and the Ferrara Cancer Registry. Tissue collection was conformed to the Institutional Research Board regulations of the University Hospitals of Ferrara. The protocol of this study was approved 
by the board of the Ministry of University and Research (identification and validation of new markers of metastasizing phenotype of breast cancer, prot. MM06095812_006, 2000).

\subsection{Tissue Microarray Construction and Immunohistochemical Staining}

Tissue microarrays (TMAs) were prepared as previously described [19]. The complete tumor series was included in a total of 31 TMA blocks. Consecutive $4-\mu \mathrm{m}$ thick sections were mounted on silanized slides.

TMA sections were stained either manually or by the Ventana NexES automated immunostainer (Ventana Medical Systems/Roche, Tucson, AZ, USA) using the primary antibodies and conditions reported in Table S1 and the Supplementary Methods Section. ER, PR, HER2, ki67, p53, and GATA3 IHC staining was reported as the proportion of positive cells. Moreover, a histological score was obtained for GATA3 as the product of the percentage of positive cell nuclei (0-100\%) and the four-tier intensity score $(0,1+, 2+, 3+)$. Therefore, the final histological score ranged from 0 to 300 for each core. The IHC scoring and positivity definition threshold are detailed in the Supplementary Methods Section and in Table S1.

\subsection{Variables of Interest}

All tumors were categorized according to the WHO classification and the eighth AJCC staging system, and graded according to the Elston-Ellis grading system [20,21]; single components of TNM staging are also reported. Histotype was categorized as no special type, lobular, or other special types (including tubular, mucinous, papillary, medullary, cribriform, apocrine, and micropapillary carcinoma). The molecular classification of BC was based on surrogate definitions by means of IHC markers for ER, PR, HER2, and ki-67, according to the criteria of the 2011 St. Gallen International Breast Cancer Conference [2].

\subsection{Outcome}

Survival time to death (for any cause) was used as the outcome variable. The date of death was extracted from the local cancer registry.

\subsection{Statistical Analysis}

For the association between GATA3 positivity and categorical variables, the chisquared test (or Fisher's exact test, when appropriate) was used to estimate the $p$-value, i.e., the probability of obtaining the observed (or stronger) association under the null hypothesis. For associations between continuous and categorical variables, the Student's t-test (or the Wilcoxon's signed rank test, when appropriate) was used. The survival curves were estimated using the Kaplan-Meier method, and the log-rank test was used to measure the $p$-value. All of the markers, including ER, PR, HER2, Ki67, p53, and GATA3, were included, together with age, stage, and grade in a multivariate analysis using the Cox regression model. Hazard ratios (HRs) with 95\% confidence intervals (CIs) were used to quantify the prognostic impact of variables. Variables with a $p$-value larger than 0.2 were excluded from the model using a backward variable selection strategy. Proportional hazard assumption was visually checked using the log-log plot and the predicted vs. observed curve comparison.

The prognostic value of GATA3 in predicting OS, plotted as Kaplan-Meier survival curves, is also reported as stratified by the other main prognostic factors.

The $p$-values, as continuous variables, and 95\% CIs are reported in order to show the probability that a difference or an association is observed for a random fluctuation under the null hypothesis, but no formal statistical test has been performed. All statistical analyses were conducted using Stata version 13.0 (StataCorp, College Station, TX, USA), and GraphPad Prism 5 software (GraphPad Software, Inc., San Diego, CA, USA) was used to plot and compare the data. 


\section{Results}

\subsection{Association between GATA3 Expression and Clinico-Pathological Features}

Clinico-pathological and IHC characteristics of the 702 patients included in this study are summarized in Table 1 and detailed in the Supplementary Materials Section.

Table 1. Clinico-pathological characteristics and biological markers of breast cancer patients.

\begin{tabular}{|c|c|}
\hline Clinico-Pathological Characteristics & n (\%) \\
\hline Age, total & 702 \\
\hline$\overline{<50 \text { years }}$ & $166(23.6)$ \\
\hline $50-55$ years & 96 (13.7) \\
\hline $56-70$ years & $265(37.7)$ \\
\hline$>70$ years & 175 (24.9) \\
\hline Grade, total & 700 \\
\hline$\frac{1}{1}$ & $135(19.2)$ \\
\hline 2 & $427(60.8)$ \\
\hline 3 & $138(19.7)$ \\
\hline Histotype, total & 702 \\
\hline$\overline{\text { No special type }}$ & $527(75.1)$ \\
\hline Lobular & $109(15.5)$ \\
\hline Other special types & $66(9.4)$ \\
\hline $\mathrm{pT}$, total & 699 \\
\hline T1 & $450(64.4)$ \\
\hline $\mathrm{T} 2$ & $236(33.8)$ \\
\hline $\mathrm{T} 3$ & $13(1.8)$ \\
\hline $\mathrm{pN}$, total & 702 \\
\hline$\frac{\mathrm{N} 0}{\mathrm{~N}}$ & $393(56.0)$ \\
\hline N1 & $184(26.2)$ \\
\hline N2 & $72(10.3)$ \\
\hline N3 & $53(7.5)$ \\
\hline \multicolumn{2}{|l|}{ Overall survival, failures } \\
\hline Five-year & $119(17.7)$ \\
\hline 10-year & $237(33.8)$ \\
\hline 15-year & $291(41.5)$ \\
\hline 20-year & $375(53.4)$ \\
\hline 28-year & $432(61.5)$ \\
\hline ER median, range & $85.2 \%, 0-98.9 \%$ \\
\hline ER, total & 665 \\
\hline Negative $(<1 \%)$ & $123(18.5)$ \\
\hline Positive $(\geq 1 \%)$ & $542(81.5)$ \\
\hline PR median, range & $57.4 \%, 0-98.9 \%$ \\
\hline PR, total & 663 \\
\hline Negative $(<1 \%)$ & $164(24.7)$ \\
\hline Positive $(\geq 1 \%)$ & $499(75.3)$ \\
\hline Ki-67 median, range & $7.0 \%, 0-98.2 \%$ \\
\hline Ki-67, total & 658 \\
\hline Negative $(<20 \%)$ & $500(76.0)$ \\
\hline Positive $(\geq 20 \%)$ & $158(24.0)$ \\
\hline HER2, total & 676 \\
\hline Negative $(0-2+)$ & $555(82.1)$ \\
\hline Positive (3+) & $121(17.9)$ \\
\hline p53 median, range & $13.0 \%, 0-98.5 \%$ \\
\hline p53, total & 660 \\
\hline Wild-type pattern & $503(76.2)$ \\
\hline Mutated pattern & $157(23.8)$ \\
\hline GATA3 score median, range & $60,0-300$ \\
\hline GATA3, total & 608 \\
\hline Negative $(<1 \%)$ & $195(32.1)$ \\
\hline Positive $(\geq 1 \%)$ & $413(67.9)$ \\
\hline Molecular intrinsic subtypes, total & 646 \\
\hline Luminal A & $274(39.0)$ \\
\hline Luminal B & $185(26.4)$ \\
\hline Luminal B-HER2+ & $80(11.4)$ \\
\hline HER2+ & $37(5.3)$ \\
\hline Triple negative & $70(10.0)$ \\
\hline
\end{tabular}


Overall, GATA3 was evaluable in 608 (87\%) of the 702 BC cases, and was positive $(\geq 1 \%)$ in $413(68 \%)$ cases and negative $(<1 \%)$ in $195(32 \%)$ cases, with a GATA3 median percentage of $50 \%$ (range $0-100 \%$ ) and a median histological score of 60 (Figure $1 \mathrm{~A}$ ). The remaining 94 TMA cores (13.4\%) were not evaluable for GATA3 due to tissue loss, unrepresentative tissue, or non-specific staining.
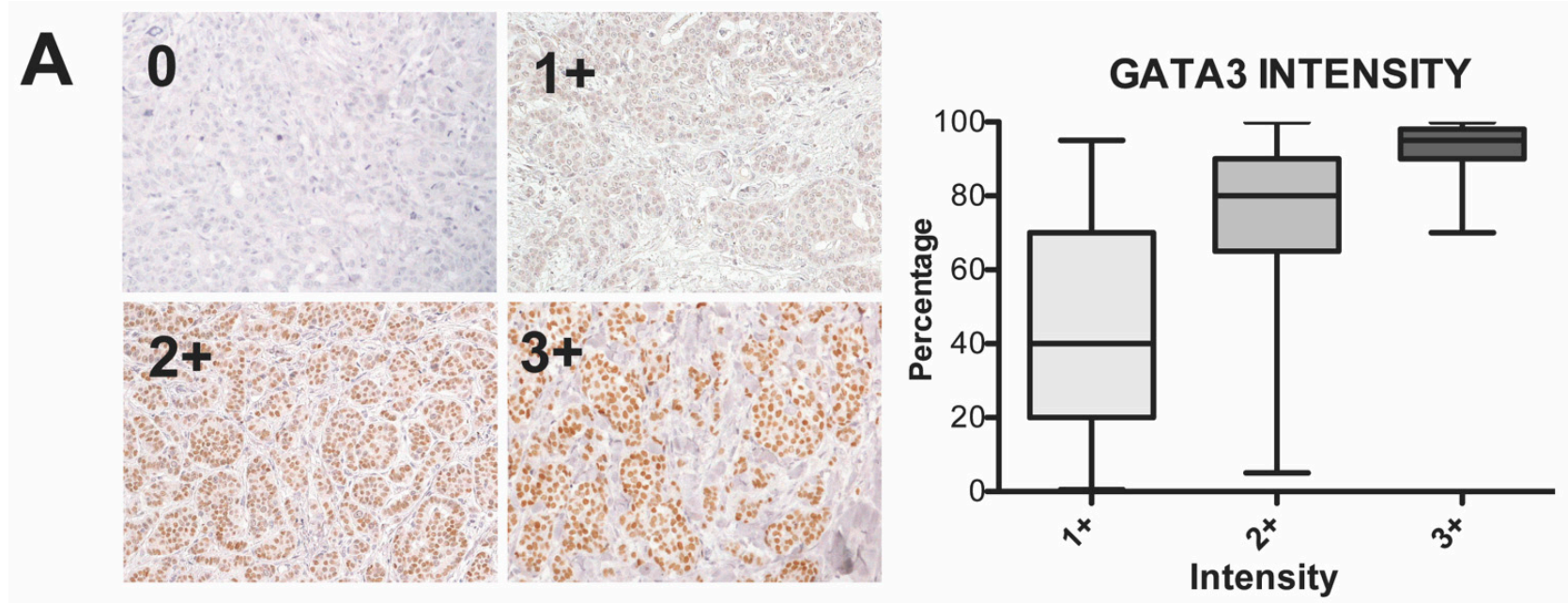

B IHC MARKERS
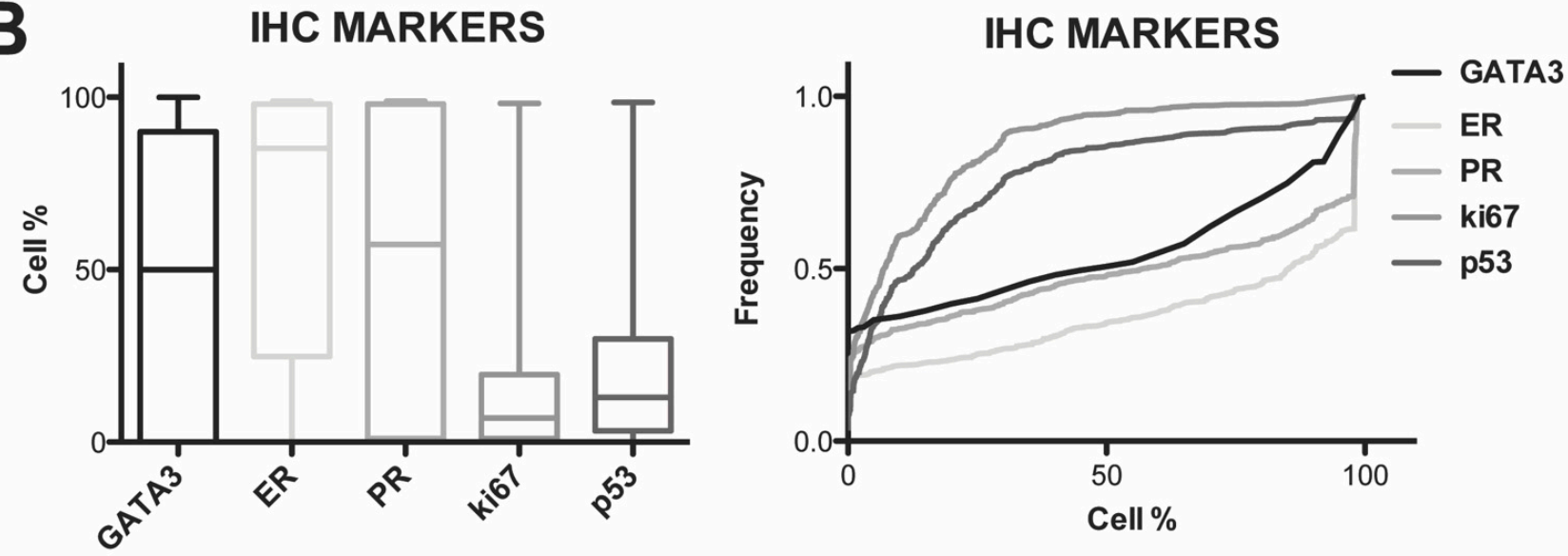

Figure 1. Representative pictures of immunostaining intensity scores of GATA3 in BC tissues and box plot diagrams (top left and top right panels, respectively) illustrating the results of GATA3 staining of 608 BC samples as positive cell percentage according to intensity scores. The differences between percent positive cells based on intensity were significant ( $p$-value $<0.0001$, Mann-Whitney U test, two-sided, right panel) (A). Box plot (bottom left) and cumulative relative frequency charts (bottom right) showing the percentage distribution of the immunohistochemical markers, including estrogen receptors (ER), progesterone receptor (PR), Ki-67 proliferation index, p53 oncosuppressor gene, and GATA3 (B).

GATA3 IHC positivity was associated with ER $(p<0.0001)$, PR $(p<0.0001)$, p53 wildtype pattern $(p<0.0001)$, and HER2 negative status $(p=0.0175)$ (Supplementary Table S2 and Figures $1 \mathrm{~B}$ and 2). A weak association was found between the GATA3 and ki67 proliferation index $(p=0.3575)$.

GATA3 positivity decreased with histological grade $(p<0.0001)$, stage grouping $(p=0.0049)$, and pT staging $(p=0.0463)$ (Figure 3). Therefore, GATA3 expression was higher in BCs with less aggressive clinico-pathological characteristics, such as grade 1 and grade 2, smaller tumor size, and lower stage than in BCs with worse prognosis characteristics. In contrast, GATA3 expression showed almost no association with age and $\mathrm{pN}$ staging $(p=0.3695$ and $p=0.845)$. 

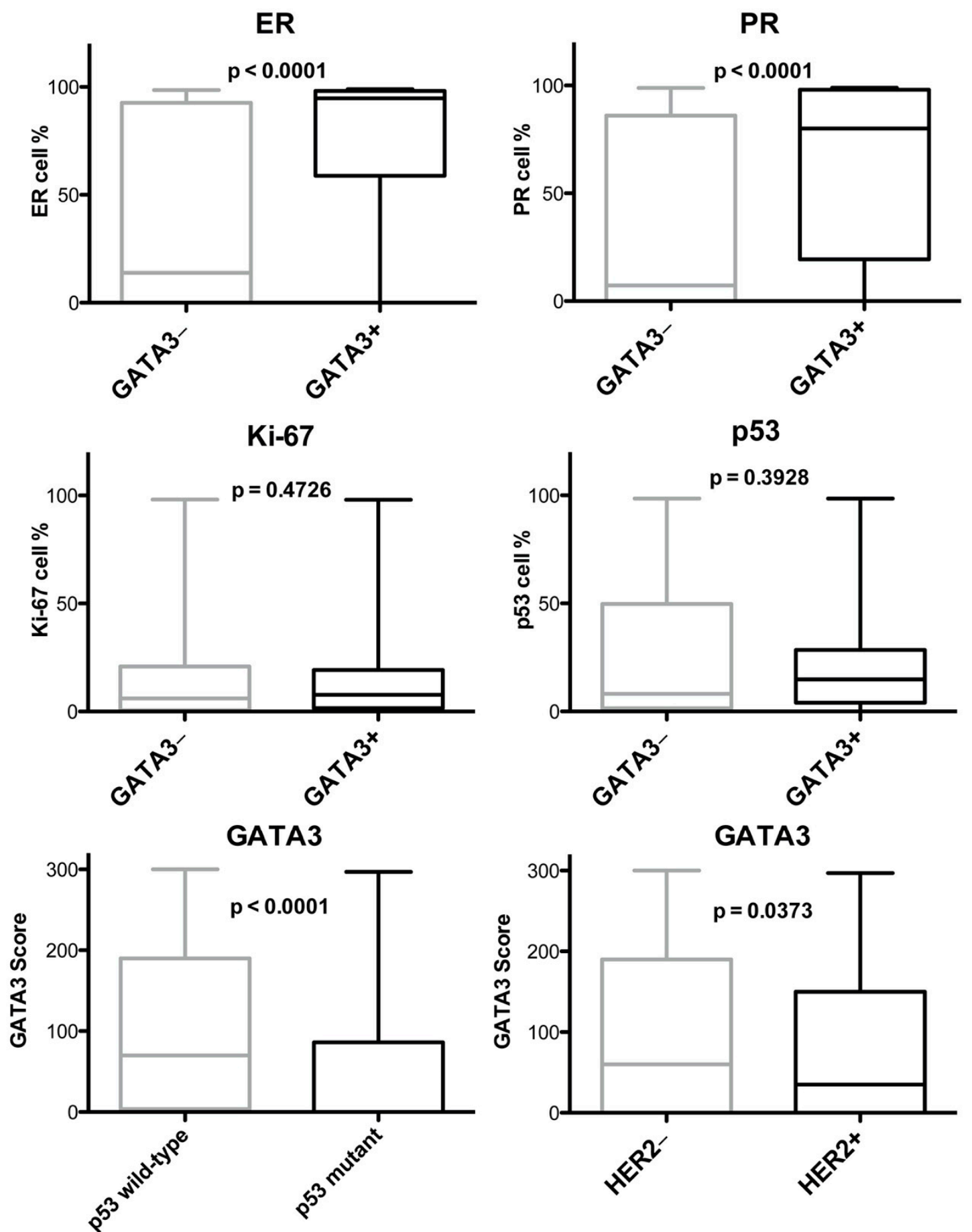

Figure 2. Box-plot charts showing the correlation between GATA3 expression (i.e., - is $<1 \%$; + is $\geq 1 \%$ ) and the biological factors ER, PR, proliferative index Ki-67, and p53, and the box plot chart of the GATA3 histological score according to p53 immunohistochemical pattern and HER2 status; $p$-values from the two-sided $t$-test comparisons are reported.

\subsection{Association between GATA3 Expression and Molecular Subtypes}

Among the BCs with scored GATA3, 576 cases were subclassified in molecular subtypes according to IHC biological markers (Table S3 and Figure S1). GATA3 positivity was higher in luminal A, luminal B-HER2-, and luminal B-HER2+ subtypes (chi-squared test, $p<0.0001)$. 


\subsection{GATA3 Expression as a Predictor of Prognosis}

In our patients with a median follow-up of 183 months, GATA3 IHC positivity was associated with better overall survival (OS, median 234 vs. 181 months for GATA3+ vs. GATA3-). Specifically, after adjusting for age, the overall hazard ratio for death was 0.70 ( $95 \%$ CI: 0.56 to $0.86, p=0.001$ ) for BC patients with positive GATA3 when compared with negative GATA3 (Figure 4 and Table S4).
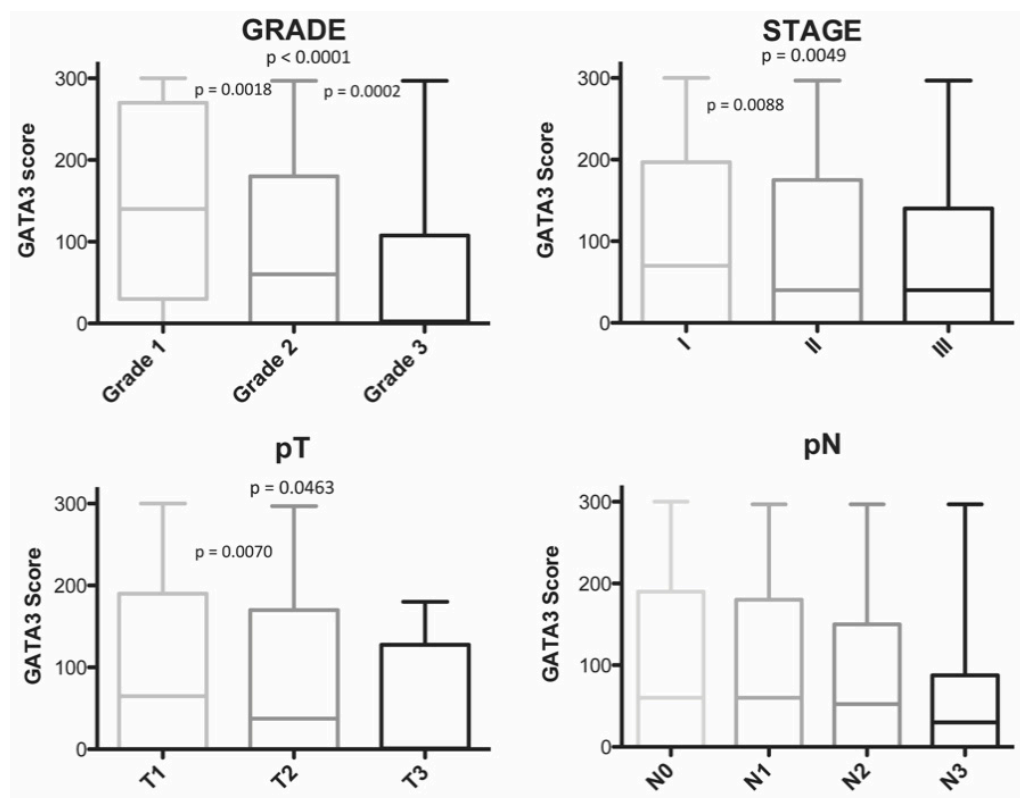

Figure 3. Box plot showing the correlation between GATA3 score and histological grade, stage grouping, pathological primary tumor size (pT), and pathological lymph node involvement $(\mathrm{pN})$. Significant $p$-values from two-sided $t$-test comparisons are reported.

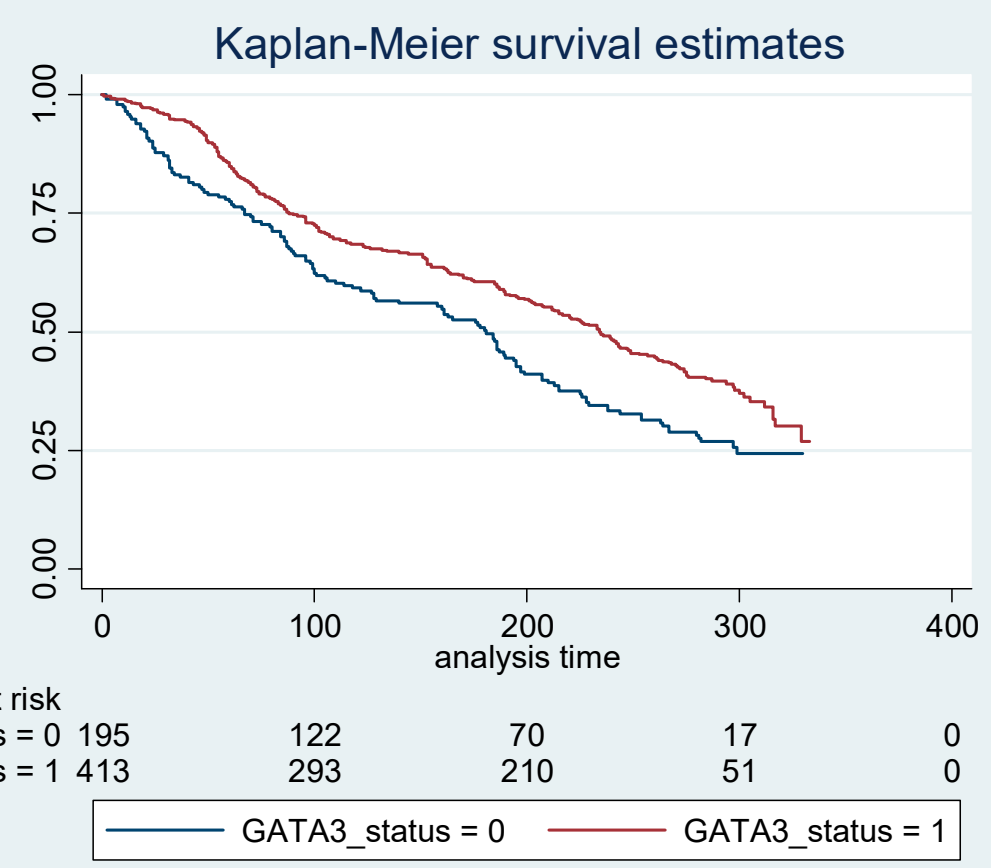

Figure 4. Kaplan-Meier survival curve analysis of GATA3 in breast carcinomas. The age-adjusted hazard ratio for death was 0.70 (95\% confidence interval 0.56-0.86). 
In order to explore the prognostic value of GATA3 positivity in different subgroups, we compared the OS curves from our BC cohort, and stratified according to the main prognostic factors (Table 2, Figure 5, and Supplementary Figure S2). GATA3 was associated to OS only in women aged 50 years or older. Analysis by grade-, pT-, and stage-specific OS according to GATA3 IHC showed a better outcome associated with GATA3 positivity, mainly among patients with a lower grade and lower stage (Table 2 and Supplementary Figure S2). Specifically, GATA3 positivity was associated with a better prognosis in BC patients older than 50 years, and with an Elston and Ellis grade of 1-2 (HR 0.69, $p=0.003$ ), pT1 (HR 0.67, $p=0.001$ ), pN0 (HR 0.65, $p=0.003$ ), and stage I-II (HR 0.65, $p<0.0001$ ). Moreover, GATA3 positivity maintained the ability to stratify patients with a better prognosis, particularly in BC subgroups with positive ER (HR 0.77, $p=0.046$ ), positive PR (HR 0.74, $p=0.022$ ), Ki-67 $<20 \%$ (HR $0.62, p=0.008$ ), negative HER2 (HR 0.64, $p<0.0001$ ), and with p53 wild-type IHC pattern (HR 0.71, $p=0.011$ ) (Table 2, Figure 5).

Table 2. The prognostic value of GATA3 positivity stratified by clinico-pathological features and biological prognostic factors. Age-adjusted HRs are estimated through proportional hazard Cox models.

\begin{tabular}{|c|c|c|}
\hline \multirow{2}{*}{ Variable } & \multicolumn{2}{|c|}{ Stratified Cox Regression Analysis } \\
\hline & Hazard Ratio & 95\% Confidence Interval \\
\hline \multicolumn{3}{|l|}{ Age } \\
\hline$<5 \overline{0 \text { years }}$ & 0.92 & $0.53-1.60$ \\
\hline$\geq 50$ years & 0.66 & $0.52-0.83$ \\
\hline \multicolumn{3}{|l|}{ Histologic Grade } \\
\hline $1-2$ & 0.69 & $0.54-0.88$ \\
\hline 3 & 0.74 & $0.47-1.16$ \\
\hline \multicolumn{3}{|l|}{ Histologic Type } \\
\hline$\overline{\text { No special type }}$ & 0.71 & $0.56-0.91$ \\
\hline Lobular & 0.69 & $0.39-1.22$ \\
\hline Other & 0.35 & $0.15-0.85$ \\
\hline \multicolumn{3}{|l|}{$\mathrm{pT}$} \\
\hline$\frac{\mathrm{T}}{\mathrm{T} 1}$ & 0.67 & $0.50-0.90$ \\
\hline $\mathrm{T} 2$ & 0.78 & $0.56-1.08$ \\
\hline T3 & 1.85 & $0.41-8.41$ \\
\hline \multicolumn{3}{|l|}{$\mathrm{pN}$} \\
\hline $\mathrm{N} 0$ & 0.65 & $0.48-0.87$ \\
\hline $\mathrm{N}+$ & 0.76 & $0.56-1.03$ \\
\hline Stage & 0.69 & \\
\hline$\frac{\mathrm{O}}{\mathrm{I}}$ & 0.69 & $0.48-1.00$ \\
\hline II & 0.66 & $0.47-0.91$ \\
\hline III & 0.96 & $0.61-1.49$ \\
\hline \multicolumn{3}{|l|}{ ER } \\
\hline Negative $(<1 \%)$ & 0.55 & $0.30-1.00$ \\
\hline Positive $(\geq 1 \%)$ & 0.77 & $0.59-0.99$ \\
\hline \multicolumn{3}{|l|}{$\mathrm{PR}$} \\
\hline Negative $(<1 \%)$ & 0.72 & $0.47-1.10$ \\
\hline Positive $(\geq 1 \%)$ & 0.74 & $0.57-0.96$ \\
\hline \multicolumn{3}{|l|}{ Ki-67 } \\
\hline Negative $(<20 \%)$ & 0.72 & $0.56-0.92$ \\
\hline Positive ( $\geq 20 \%)$ & 0.67 & $0.44-1.02$ \\
\hline \multicolumn{3}{|l|}{ HER2 } \\
\hline Negative $(0-2+)$ & 0.64 & $0.51-0.82$ \\
\hline Positive $(3+)$ & 1.06 & $0.66-1.71$ \\
\hline \multicolumn{3}{|c|}{ Molecular intrinsic BC subtypes } \\
\hline Luminal A & 0.78 & $0.54-1.14$ \\
\hline Luminal B & 0.64 & $0.42-0.98$ \\
\hline Luminal B-HER2+ & 1.17 & $0.62-2.21$ \\
\hline HER2+ & 0.66 & $0.18-2.36$ \\
\hline Triple negative & 0.69 & $0.33-1.46$ \\
\hline \multicolumn{3}{|l|}{ p53 } \\
\hline Wild-type pattern & 0.71 & $0.55-0.92$ \\
\hline Mutated pattern & 0.93 & $0.61-1.41$ \\
\hline
\end{tabular}

n, number of cases; ER, estrogen receptor; PR, progesterone receptor. 


\section{ER+}

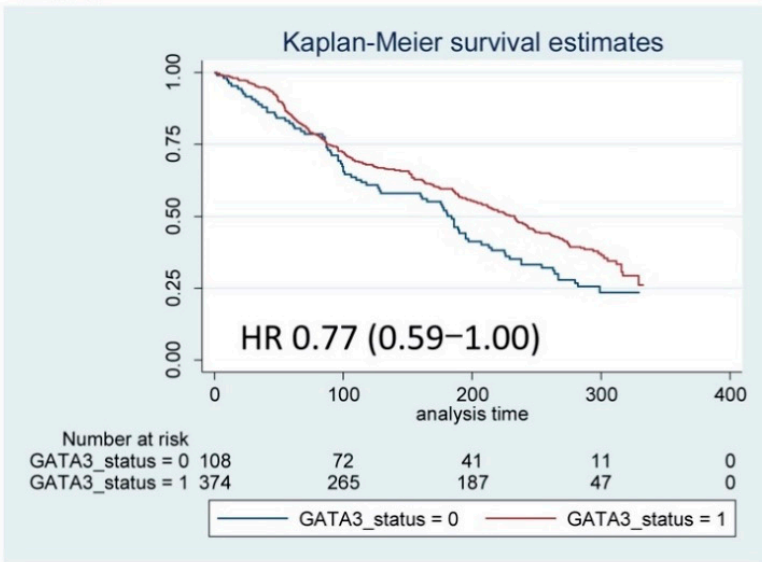

\section{Ki67-}

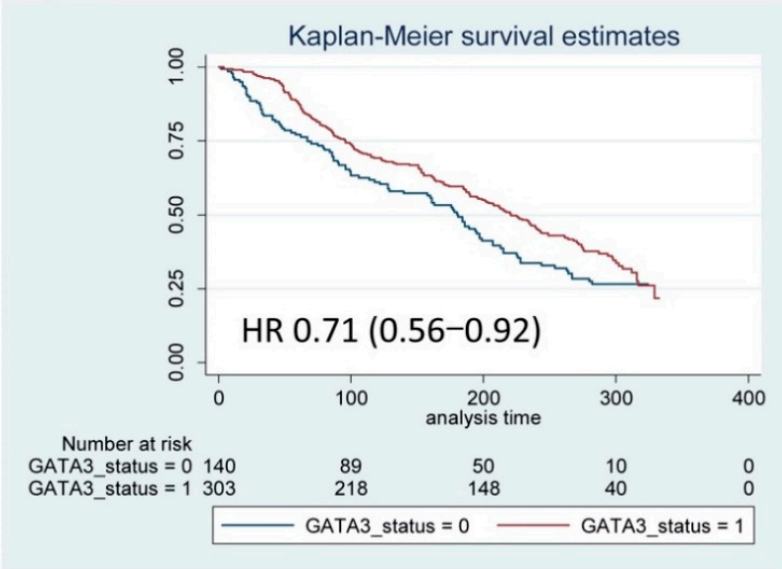

\section{Wild-type p53}

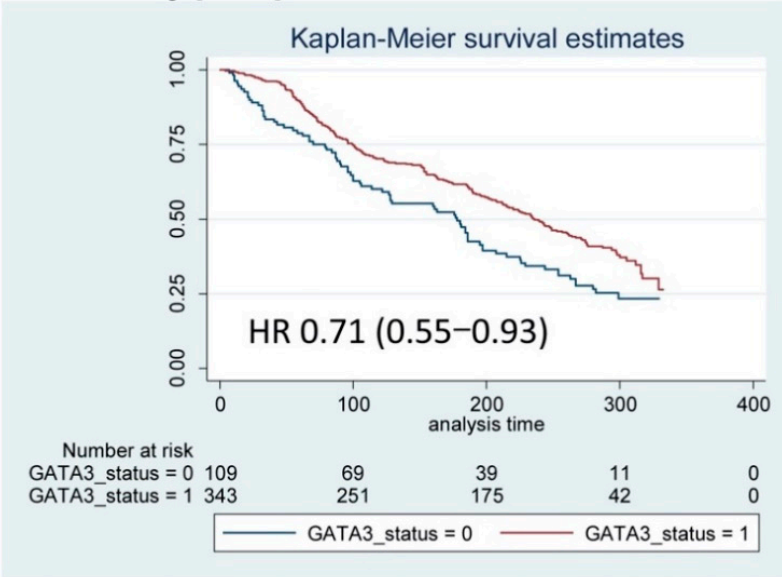

\section{PR+}

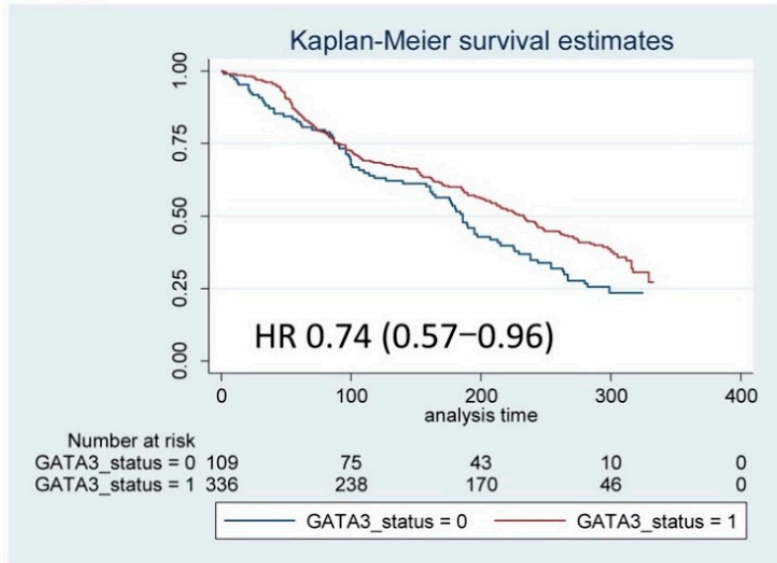

HER2-

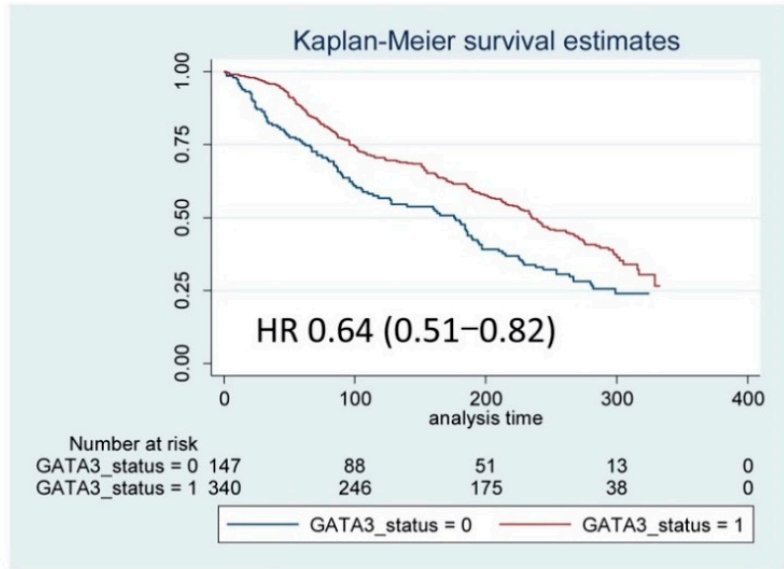

\section{Luminal B}

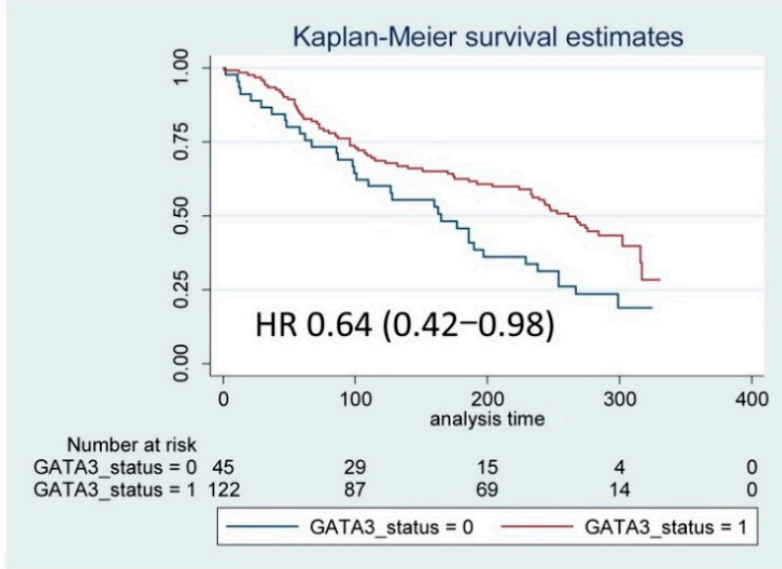

Figure 5. Kaplan-Meier overall survival curves of subgroups of breast cancer patients according to IHC expression of GATA3. After adjusting for the patients' age, GATA3 IHC positivity was associated with a significantly better overall survival in breast carcinoma patients with positive (+) estrogen receptors (ER) and progesterone receptor (PR), negative (-) HER2 and Ki-67 (i.e., $<20 \%$ ), and p53 wild-type IHC pattern and Luminal B intrinsic subtype. The age-adjusted hazard ratio (HR) for death and the $95 \%$ confidence interval (CI) estimated with Cox regression analyses are reported.

Furthermore, GATA3 expression was associated with a better OS of BC patients with luminal B intrinsic subtype (median survival 261 vs. 166 months for GATA3+ vs. GATA3- 
, HR $0.64,95 \%$ CI: 0.42 to $0.97, p=0.036$ ), but not with the other molecular subtypes (Figure 5). Notably, the opposite trend was observed in patients with positive HER2 (HR 1.06, 95\% CI: 0.66 to 1.71, $p=0.798$ ), in which GATA3 positivity was associated with worse OS, but this association was compatible with random fluctuation (Table 2).

According to the log-log plot and predicted versus observed survival curves, GATA3 was a time-independent variable. As a consequence, we could apply the Cox proportional hazards modeling. After adjusting for all clinico-pathological and IHC variables, stage, GATA3, and p53 functioned as independent prognostic factors for BC patients (Table 3).

Table 3. Multivariate Cox proportional hazards model for the overall survival.

\begin{tabular}{|c|c|c|c|c|}
\hline \multirow[b]{3}{*}{ Variables } & \multicolumn{3}{|c|}{ Multivariate Cox Regression Analysis } & \\
\hline & \multicolumn{2}{|c|}{ Entire Follow Up Time* } & \multicolumn{2}{|c|}{ 48-Month Follow-Up } \\
\hline & Hazard Ratio & $95 \%$ CI & Hazard Ratio & $95 \%$ CI \\
\hline Age & 1.06 & $1.05-1.07$ & 1.03 & $1.01-1.05$ \\
\hline GATA3 & 0.79 & $0.63-0.99$ & 0.60 & $0.37-0.99$ \\
\hline$\overline{p 53}$ & 1.31 & $1.02-1.68$ & 2.07 & $1.24-3.46$ \\
\hline \multicolumn{5}{|l|}{ Stage } \\
\hline I & 1 & & 1 & \\
\hline II & 1.24 & $0.98-1.57$ & 2.11 & $1.10-4.05$ \\
\hline III & 2.55 & $1.96-3.42$ & 3.84 & $1.95-7.54$ \\
\hline \multicolumn{5}{|l|}{ Grade } \\
\hline 1 & Not influential & & 1 & \\
\hline 2 & & & 2.67 & $0.81-8.78$ \\
\hline 3 & & & 3.83 & $1.11-13.24$ \\
\hline
\end{tabular}

Differently, based on the log-log plot and predicted vs. observed survival curves, for grade, ER, PR, HER2, Ki-67, and p53, the risks were not proportional, and the Cox model did not correctly predict survival during the whole time period, but just during the first 48 months after surgical treatment. As a consequence, we applied a univariate Cox regression analysis in this limited time period, and found that all covariates had a significant impact on short-term OS (Table S5). Afterward, multivariate analysis on this time period showed that GATA3 IHC positivity was an independent and favorable predictive factor for improved OS in BC patients, reducing the hazard ratio by $40 \%$ (Table 3). In addition, the p53 mutation IHC pattern was an independent risk factor for reduced OS, increasing the hazard ratio two-fold (Table 3). Among the other prognostic factors, only stage and grade remained associated at 48 months. Table S5 shows the association of each biomarker with the 48 -month OS adjusted by age and stage.

\section{Discussion}

We found that GATA3 expression was associated with a $20 \%$ reduction in the risk of death during a 28-year follow-up time. Only p53 had a comparable impact on OS, with a $30 \%$ higher risk of death. The prognostic value of the two biomarkers was even stronger in the first 48 months of follow-up. No other tumor characteristic showed a stronger association with overall survival.

Moreover, we found that GATA3 association with OS was also maintained in individual BC subgroups, particularly those at lower risk, such as ER-positive, PR-positive, HER2-negative, with lower proliferation (ki-67<20\%), p53 wild-type, lower grade, smaller size (pT1-T2), without lymph node metastasis (pN0), at lower stage, and older than 50 years.

GATA3 is an ER-related gene and, as such, has been associated with improved outcome in BC patients $[16,17,22]$. However, conclusive data demonstrating GATA3 as a prognostic factor independent of ER status are still missing [18]. In our study, we found that $68 \%$ of BCs expressed GATA3 by IHC. Previous studies have reported that GATA3 IHC expression ranged between $31 \%$ and $92 \%$ in BCs [18,23-25]. The apparent discrepancy in GATA3 expression between these studies may reflect both the methodology used and the different 
cutoff values assigned to define GATA3 IHC positivity [26,27]. In our study, we used TMA with relatively large cores, and the positive GATA3 IHC cutoff was set at $1 \%$ (to parallel cutoff percentages of ER and PR), obtaining a high positive rate [1]. Moreover, the assessment of positive IHC can be subjective and operator-dependent; to limit the impact of this variability and to increase score accuracy, we applied an automated scoring method [28].

Consistently with all previous studies, we found an excellent correlation $(p<0.0001)$ between hormone receptor positivity and GATA3 expression [16,25,29,30]. In fact, in our study, 78\% of ER-positive and 76\% of PR-positive BCs were also GATA3 positive, and, vice versa, 93\% were also ER-positive and $85 \%$ were PR-positive among GATA3-positive cases. These results are coherent with the integral role of GATA3 in the ER signaling pathway revealed by both cell line studies and microarray data analyses [30-32]. Moreover, we found a significant association between GATA3 positivity and HER2 negativity. Our results are consistent with the majority of the previous studies that have investigated this relationship $[18,23,33,34]$, but not with all of them $[29,35,36]$. Notably, these associations reflect the GATA3 distribution between BC molecular subtypes.

In addition to usual biological prognostic factors, we evaluated p53 IHC. TP53 is the most commonly mutated gene in BC, given that TP53 mutations occur in 30\% of BCs $[13,14,37]$. Importantly, TP53 mutation has been strongly associated with a worse outcome in BC patients [38,39]. First, we found no association between GATA3 expression and p53 by IHC percentage, similarly to Hosoda et al. and Jacquemier et al. [36,40]. Conversely, two different studies have identified higher p53 expression in GATA3-negative BCs $[33,34]$. Therefore, we categorized p53 IHC in patterns associated with mutated and wild-type TP53 status [41-43]. In this way, we found a positive association between GATA3 positivity and p53 wild-type pattern. This novel finding is reasonably expected, since GATA3 and TP53 mutations have been shown to be mutually exclusive in BCs [14].

Interestingly, our results in terms of survival associate mutant p53 pattern with an exceedingly worse prognosis at 48 months (HR 2.73) are in agreement with previous studies [38]. Therefore, our results further bolster p53 IHC as a prognostic test in BC tissues.

Looking at clinico-pathological parameters, based on our findings, GATA3 positivity is inversely associated with the most important clinical prognostic factors of BC outcome, namely tumor size and lymph node metastasis. Most of the previous studies that have examined GATA3 IHC expression in relation with tumor size and/or the presence of lymph node metastasis did not find any association [23,29,33,44-46]; however, four studies analogously reported an inverse association between GATA3 and tumor size [16-18,45], and only one reported low GATA3 expression associated with lymph node metastasis [16].

Altogether, our findings associate, univocally and clearly, GATA3 expression to favorable clinical, biological, and pathological features of $\mathrm{BC}$, coherently with and supporting previous observations.

To date, there is still undisguised controversy regarding the ability of GATA3 to predict the long-term prognosis in BC patients. Specifically, although a high GATA3 gene expression level has been convincingly associated with a better outcome of BC patients independently of other clinico-pathological features [16,47-49], the prognostic value of the GATA3 protein level by IHC remains inconclusive [16-18,35,50].

Among intrinsic molecular subtypes, GATA3 expression was associated with a better OS in luminal B. It is well-known that different intrinsic molecular subtypes show distinct clinical evolutions. Characteristically, luminal B BC has a poorer outcome compared with luminal A, but similar to HER2-positive and TNBC [51]. Furthermore, luminal B exhibits a delayed aggressive behavior with the highest mortality rate after five to eight years when compared to HER2-positive and TNBC that progress rapidly with the highest mortality during the first two years after the diagnosis [52]. Therefore, our results emphasize the possibility that GATA3 plays a different prognostic role in various BC intrinsic subtypes. This should be kept in mind for further studies in order to better clarify the additional 
prognostic information supplied by GATA3 for therapeutic decision-making, especially in luminal B BCs.

A non-negligible number of studies have investigated the prognostic value of GATA3 by IHC in continuous series of BCs. The first study by Mehra et al. has analyzed GATA3 IHC in a cohort of 139 consecutive invasive BCs arranged in TMA blocks, and has found that BC patients with low GATA3 expression had significantly shorter OS [16]. However, the prognostic value of GATA3 IHC was not independent of other prognostic variables by a Cox multivariate analysis of OS. Similarly, Voduc et al. could not demonstrate GATA3 IHC as an independent prognostic predictor in over 3100 consecutive cases of BCs, as well as in the ER-positive subgroup [18]. Analogously, in the same year, Ciocca et al. found a non-significant modest protective effect of GATA3 positivity in the OS of 166 consecutive BC patients [50]. No association between GATA3 expression and outcome was found by Albergaria et al. in 249 consecutive BC patients [23]. Thereafter, Yoon et al. could not only confirm the association of GATA3 IHC positivity with better BC-related survival in a consecutive series of $242 \mathrm{BC}$ and in the ER-positive subgroup, but also found it in lowgrade groups [17]. Two studies in particular have investigated over 200 hormone receptorpositive and HER2-negative BCs, and both found that GATA3 was significantly associated with a better prognosis in univariate analysis, but not in multivariate analysis [36,45]. Then, McCleskey et al. obtained analogous results by analyzing 62 advanced BC patients [53].

Another study has specifically evaluated the impact of GATA3 prognostics on $516 \mathrm{BC}$ patients treated with systemic therapy, i.e., chemotherapy and/or tamoxifen [35]. GATA3 status could not reveal significant differences in OS among these patients, but GATA3 positivity negatively affected the OS of ER-negative patients (who did not receive tamoxifen), only in the univariate analysis. Finally, two studies investigated the GATA3 prognostic effect on patients treated with neoadjuvant chemotherapy [54,55]. Both showed that GATA3 negativity was significantly associated with a more likely complete pathological response [54,55]. Notably, our patients were treated long before the introduction of current BC systemic standard treatment based on the expression of molecular markers and $\mathrm{BC}$ molecular intrinsic subtypes, which limits the applicability of our results to present-day patients, but it gives the opportunity to observe its prognostic value in a setting where therapies were given only on the basis of lymph node status, surgical margins, and tumor size.

In summary, altogether, the studies that have investigated GATA3 as a prognostic factor in $B C$ patients found that, even though GATA3 is associated with a favorable prognosis, it may not represent an independent prognostic factor, since, in the majority of the studies, GATA3 could not demonstrate its predictor value in a multivariate analysis [56]. Therefore, GATA3 has been shown so far as a critical biomarker associated with improved survival, but this association can depend on the association of GATA3 expression with different variables of good prognosis. Instead, our data showed a strong independent association of GATA3 positivity with an improved prognosis, particularly in HR-positive BCs and in BCs with a good prognosis. Ours is the second largest study that has analyzed the prognostic impact of GATA3 IHC, and it is worth noting that results from the two largest studies confirmed an independent association with the prognosis, even in stratified analyses by cancer subtype, that smaller studies could not detect. More generally, our results emphasize the possibility that GATA3 plays a different prognostic role in various BC subtypes; this should be kept in mind for further studies in order to better clarify the additional prognostic information supplied by GATA3 for therapeutic decision-making, especially in luminal $B$ BCs. In fact, there is an unmet need to identify patients with luminal A and B cancers who may benefit from adjuvant chemotherapy, particularly among those without early BC [5,57-59]. Therefore, given our results, GATA3 should be explored as a potential biomarker to help define the prognosis of early HR-positive BC, and could demonstrate an immediate, clinically-relevant application in this context and for this specific clinical issue. 


\section{Conclusions}

Our study, building on previous observations, provides new evidence of the prognostic value of GATA3 in $\mathrm{BC}$, inasmuch as it correlates GATA3 negativity to a worse prognosis, especially in less aggressive BC subgroups. Indeed, GATA3 IHC could uncover BC patients with worse clinical outcomes in low-risk categories, which would potentially benefit from additional tailored treatment. Our data, therefore, support the possible clinical utility of incorporating GATA3 IHC analysis into routine practice as an adjunct to standard IHC panel, in order to further risk-stratify BC patients at a remarkably low cost when compared to multigene prognostic tests. Since GATA3 IHC is currently used in routine diagnostic practice as a surrogate marker for breast and urothelial origins of carcinomas of unknown primary, this should be straightforward, however, standardized methods with a univocal and reproducible cutoff are needed.

Supplementary Materials: The following are available online at https:/ /www.mdpi.com/article/10 .3390/diagnostics11040604/s1, Supplementary Material and Methods, Results, Figure S1: distribution by molecular subtypes and GATA3, Figure S2: Kaplan-Meier overall survival curves in different breast cancer subgroups, Table S1: primary antibodies and conditions used in this study, Table S2: association between GATA3 and clinico-pathological characteristics of breast cancer patients, Table S3: correlation between GATA3 and molecular subtypes, Table S4: Kaplan-Meier survival analysis for the linic-pathological features and biological prognostic factors, Table S5: univariate, age-adjusted, and age and stage-adjusted hazard ratios estimated through proportional hazards Cox regression analysis for the overall survival at 48 months follow-up.

Author Contributions: Conceptualization, P.Q. and E.K.; methodology, M.P., P.G.R. and E.K.; formal analysis, P.Q., M.P., R.R., P.G.R. and E.K.; resources, P.Q.; data curation, P.G.R. and E.K.; supervision, P.S.; Writing-Original draft preparation, E.K.; Writing—Review and editing, P.Q., M.P., R.R., P.S., P.G.R. and E.K.; visualization, E.K. All authors have read and agreed to the published version of the manuscript.

Funding: This research received no external funding.

Institutional Review Board Statement: This study was conducted according to the guidelines of the Declaration of Helsinki, and approved by the Institutional Research Board regulations of the University Hospitals of Ferrara, and the protocol was approved by the board of the Ministry of the University and Research (identification and validation of new markers of metastasizing phenotype of breast cancer, prot. MM06095812_006, year 2000).

Informed Consent Statement: Patient consent was waived due to the use of archival data of an anonymous nature that does not disclose patients' identity.

Data Availability Statement: All data generated or analyzed during this study are included in this published article and its Supplementary Information File.

Acknowledgments: We thank Eros Magri and Anna Cherubino for their technical assistance.

Conflicts of Interest: The authors declare no conflict of interest.

\section{References}

1. Goldhirsch, A.; Winer, E.P.; Coates, A.S.; Gelber, R.D.; Piccart-Gebhart, M.; Thurlimann, B.; Senn, H.J.; Panel, M. Personalizing the treatment of women with early breast cancer: Highlights of the St Gallen International Expert Consensus on the Primary Therapy of Early Breast Cancer 2013. Ann. Oncol. 2013, 24, 2206-2223. [CrossRef] [PubMed]

2. Goldhirsch, A.; Wood, W.C.; Coates, A.S.; Gelber, R.D.; Thurlimann, B.; Senn, H.J.; Panel, M. Strategies for subtypes-Dealing with the diversity of breast cancer: Highlights of the St. Gallen International Expert Consensus on the Primary Therapy of Early Breast Cancer 2011. Ann. Oncol. 2011, 22, 1736-1747. [CrossRef] [PubMed]

3. McGuire, W.L.; Clark, G.M. Prognostic factors and treatment decisions in axillary-node-negative breast cancer. N. Engl. J. Med. 1992, 326, 1756-1761. [CrossRef] [PubMed]

4. European Commission Initiative on Breast Cancer. Recommendations from the European Breast Cancer Guidelines. Available online: https:/ / healthcare-quality.jrc.ec.europa.eu/european-breast-cancer-guidelines/towards-the-treatment-of-invasive-cancer (accessed on 2 February 2021). 
5. NICE National Institute for Health Care and Excellence. Tumour Profiling Tests to Guide Adjuvant Chemotherapy Decisions in Early Breast Cancer. Diagnostic Guidance DG34. Available online: https://www.nice.org.uk/guidance/dg34/resources/tumourprofiling-tests-to-guide-adjuvant-chemotherapy-decisions-in-early-breast-cancer-pdf-1053750722245 (accessed on 2 February 2021).

6. $\quad$ Asselin-Labat, M.L.; Sutherland, K.D.; Barker, H.; Thomas, R.; Shackleton, M.; Forrest, N.C.; Hartley, L.; Robb, L.; Grosveld, F.G.; van der Wees, J.; et al. Gata-3 is an essential regulator of mammary-gland morphogenesis and luminal-cell differentiation. Nat. Cell Biol. 2007, 9, 201-209. [CrossRef]

7. Ting, C.N.; Olson, M.C.; Barton, K.P.; Leiden, J.M. Transcription factor GATA-3 is required for development of the T-cell lineage. Nature 1996, 384, 474-478. [CrossRef]

8. Kouros-Mehr, H.; Slorach, E.M.; Sternlicht, M.D.; Werb, Z. GATA-3 maintains the differentiation of the luminal cell fate in the mammary gland. Cell 2006, 127, 1041-1055. [CrossRef]

9. Tkocz, D.; Crawford, N.T.; Buckley, N.E.; Berry, F.B.; Kennedy, R.D.; Gorski, J.J.; Harkin, D.P.; Mullan, P.B. BRCA1 and GATA3 corepress FOXC1 to inhibit the pathogenesis of basal-like breast cancers. Oncogene 2012, 31, 3667-3678. [CrossRef]

10. Dydensborg, A.B.; Rose, A.A.; Wilson, B.J.; Grote, D.; Paquet, M.; Giguere, V.; Siegel, P.M.; Bouchard, M. GATA3 inhibits breast cancer growth and pulmonary breast cancer metastasis. Oncogene 2009, 28, 2634-2642. [CrossRef]

11. Yan, W.; Cao, Q.J.; Arenas, R.B.; Bentley, B.; Shao, R. GATA3 inhibits breast cancer metastasis through the reversal of epithelialmesenchymal transition. J. Biol. Chem. 2010, 285, 14042-14051. [CrossRef]

12. Usary, J.; Llaca, V.; Karaca, G.; Presswala, S.; Karaca, M.; He, X.; Langerod, A.; Karesen, R.; Oh, D.S.; Dressler, L.G.; et al. Mutation of GATA3 in human breast tumors. Oncogene 2004, 23, 7669-7678. [CrossRef]

13. Pereira, B.; Chin, S.F.; Rueda, O.M.; Vollan, H.K.; Provenzano, E.; Bardwell, H.A.; Pugh, M.; Jones, L.; Russell, R.; Sammut, S.J.; et al. The somatic mutation profiles of 2433 breast cancers refines their genomic and transcriptomic landscapes. Nat. Commun. 2016, 7, 11479. [CrossRef]

14. Cancer Genome Atlas Network. Comprehensive molecular portraits of human breast tumours. Nature 2012, 490, 61-70. [CrossRef] [PubMed]

15. Jiang, Y.Z.; Yu, K.D.; Zuo, W.J.; Peng, W.T.; Shao, Z.M. GATA3 mutations define a unique subtype of luminal-like breast cancer with improved survival. Cancer 2014, 120, 1329-1337. [CrossRef] [PubMed]

16. Mehra, R.; Varambally, S.; Ding, L.; Shen, R.; Sabel, M.S.; Ghosh, D.; Chinnaiyan, A.M.; Kleer, C.G. Identification of GATA3 as a breast cancer prognostic marker by global gene expression meta-analysis. Cancer Res. 2005, 65, 11259-11264. [CrossRef]

17. Yoon, N.K.; Maresh, E.L.; Shen, D.; Elshimali, Y.; Apple, S.; Horvath, S.; Mah, V.; Bose, S.; Chia, D.; Chang, H.R.; et al. Higher levels of GATA3 predict better survival in women with breast cancer. Hum. Pathol. 2010, 41, 1794-1801. [CrossRef] [PubMed]

18. Voduc, D.; Cheang, M.; Nielsen, T. GATA-3 expression in breast cancer has a strong association with estrogen receptor but lacks independent prognostic value. Cancer Epidemiol. Biomark. Prev. 2008, 17, 365-373. [CrossRef]

19. Querzoli, P.; Coradini, D.; Pedriali, M.; Boracchi, P.; Ambrogi, F.; Raimondi, E.; La Sorda, R.; Lattanzio, R.; Rinaldi, R.; Lunardi, M.; et al. An immunohistochemically positive E-cadherin status is not always predictive for a good prognosis in human breast cancer. Br. J. Cancer 2010, 103, 1835-1839. [CrossRef] [PubMed]

20. Elston, C.W.; Ellis, I.O. Pathological prognostic factors in breast cancer. I. The value of histological grade in breast cancer: Experience from a large study with long-term follow-up. Histopathology 2002, 41, 154-161. [CrossRef] [PubMed]

21. Lakhani, S.R.; Ellis, I.O.; Schnitt, S.J.; Tan, P.H.; van de Vijver, M.J. WHO Classification of Tumours of the Breast, 4th ed.; International Agency for Research on Cancer: Lyon, France, 2012; Volume 4.

22. Parikh, P.; Palazzo, J.P.; Rose, L.J.; Daskalakis, C.; Weigel, R.J. GATA-3 expression as a predictor of hormone response in breast cancer. J. Am. Coll. Surg. 2005, 200, 705-710. [CrossRef] [PubMed]

23. Albergaria, A.; Paredes, J.; Sousa, B.; Milanezi, F.; Carneiro, V.; Bastos, J.; Costa, S.; Vieira, D.; Lopes, N.; Lam, E.W.; et al. Expression of FOXA1 and GATA-3 in breast cancer: The prognostic significance in hormone receptor-negative tumours. Breast Cancer Res. 2009, 11, R40. [CrossRef] [PubMed]

24. Wendroth, S.M.; Mentrikoski, M.J.; Wick, M.R. GATA3 expression in morphologic subtypes of breast carcinoma: A comparison with gross cystic disease fluid protein 15 and mammaglobin. Ann. Diagn. Pathol. 2015, 19, 6-9. [CrossRef] [PubMed]

25. Shaoxian, T.; Baohua, Y.; Xiaoli, X.; Yufan, C.; Xiaoyu, T.; Hongfen, L.; Rui, B.; Xiangjie, S.; Ruohong, S.; Wentao, Y. Characterisation of GATA3 expression in invasive breast cancer: Differences in histological subtypes and immunohistochemically defined molecular subtypes. J. Clin. Pathol. 2017, 70, 926-934. [CrossRef] [PubMed]

26. Dowsett, M.; Nielsen, T.O.; A’Hern, R.; Bartlett, J.; Coombes, R.C.; Cuzick, J.; Ellis, M.; Henry, N.L.; Hugh, J.C.; Lively, T.; et al. Assessment of Ki67 in breast cancer: Recommendations from the International Ki67 in Breast Cancer working group. J. Natl. Cancer Inst. 2011, 103, 1656-1664. [CrossRef] [PubMed]

27. Krings, G.; Nystrom, M.; Mehdi, I.; Vohra, P.; Chen, Y.Y. Diagnostic utility and sensitivities of GATA3 antibodies in triple-negative breast cancer. Hum. Pathol. 2014, 45, 2225-2232. [CrossRef] [PubMed]

28. Altman, D.G.; Lausen, B.; Sauerbrei, W.; Schumacher, M. Dangers of using "optimal" cutpoints in the evaluation of prognostic factors. J. Natl. Cancer Inst. 1994, 86, 829-835. [CrossRef]

29. Gonzalez, R.S.; Wang, J.; Kraus, T.; Sullivan, H.; Adams, A.L.; Cohen, C. GATA-3 expression in male and female breast cancers: Comparison of clinicopathologic parameters and prognostic relevance. Hum. Pathol. 2013, 44, 1065-1070. [CrossRef] 
30. Hoch, R.V.; Thompson, D.A.; Baker, R.J.; Weigel, R.J. GATA-3 is expressed in association with estrogen receptor in breast cancer. Int. J. Cancer 1999, 84, 122-128. [CrossRef]

31. Sorlie, T.; Perou, C.M.; Tibshirani, R.; Aas, T.; Geisler, S.; Johnsen, H.; Hastie, T.; Eisen, M.B.; van de Rijn, M.; Jeffrey, S.S.; et al. Gene expression patterns of breast carcinomas distinguish tumor subclasses with clinical implications. Proc. Natl. Acad. Sci. USA 2001, 98, 10869-10874. [CrossRef]

32. van de Vijver, M.J.; He, Y.D.; van't Veer, L.J.; Dai, H.; Hart, A.A.; Voskuil, D.W.; Schreiber, G.J.; Peterse, J.L.; Roberts, C.; Marton, M.J.; et al. A gene-expression signature as a predictor of survival in breast cancer. N. Engl. J. Med. 2002, 347, 1999-2009. [CrossRef]

33. Min, K.W.; Kim, D.H.; Do, S.I.; Chae, S.W.; Kim, K.; Sohn, J.H.; Pyo, J.S.; Lee, H.J.; Kim, D.H.; Oh, S.; et al. Negative association between GATA3 and fascin could predict relapse-free and overall survival in patients with breast cancer. Virchows Arch. 2016, 468, 409-416. [CrossRef]

34. Min, K.W.; Kim, D.H.; Do, S.I.; Chae, S.W.; Kim, K.; Sohn, J.H.; Lee, H.J.; Do, I.G.; Pyo, J.S.; Kim, Y.; et al. Expression Pattern of Smad4/GATA3 as a Predictor of Survival in Invasive Ductal Carcinoma of the Breast. Pathobiology 2017, 84, 130-138. [CrossRef]

35. Gulbahce, H.E.; Sweeney, C.; Surowiecka, M.; Knapp, D.; Varghese, L.; Blair, C.K. Significance of GATA-3 expression in outcomes of patients with breast cancer who received systemic chemotherapy and/or hormonal therapy and clinicopathologic features of GATA-3-positive tumors. Hum. Pathol. 2013, 44, 2427-2431. [CrossRef]

36. Hosoda, M.; Yamamoto, M.; Nakano, K.; Hatanaka, K.C.; Takakuwa, E.; Hatanaka, Y.; Matsuno, Y.; Yamashita, H. Differential expression of progesterone receptor, FOXA1, GATA3, and p53 between pre- and postmenopausal women with estrogen receptorpositive breast cancer. Breast Cancer Res. Treat. 2014, 144, 249-261. [CrossRef] [PubMed]

37. Stephens, P.J.; Tarpey, P.S.; Davies, H.; Van Loo, P.; Greenman, C.; Wedge, D.C.; Nik-Zainal, S.; Martin, S.; Varela, I.; Bignell, G.R.; et al. The landscape of cancer genes and mutational processes in breast cancer. Nature 2012, 486, 400-404. [CrossRef] [PubMed]

38. Olivier, M.; Langerod, A.; Carrieri, P.; Bergh, J.; Klaar, S.; Eyfjord, J.; Theillet, C.; Rodriguez, C.; Lidereau, R.; Bieche, I.; et al. The clinical value of somatic TP53 gene mutations in 1794 patients with breast cancer. Clin. Cancer Res. 2006, 12, 1157-1167. [CrossRef]

39. Simao, T.A.; Ribeiro, F.S.; Amorim, L.M.; Albano, R.M.; Andrada-Serpa, M.J.; Cardoso, L.E.; Mendonca, G.A.; de Moura-Gallo, C.V. TP53 mutations in breast cancer tumors of patients from Rio de Janeiro, Brazil: Association with risk factors and tumor characteristics. Int. J. Cancer 2002, 101, 69-73. [CrossRef] [PubMed]

40. Jacquemier, J.; Charafe-Jauffret, E.; Monville, F.; Esterni, B.; Extra, J.M.; Houvenaeghel, G.; Xerri, L.; Bertucci, F.; Birnbaum, D. Association of GATA3, P53, Ki67 status and vascular peritumoral invasion are strongly prognostic in luminal breast cancer. Breast Cancer Res. 2009, 11, R23. [CrossRef] [PubMed]

41. Kuhn, E.; Kurman, R.J.; Vang, R.; Sehdev, A.S.; Han, G.; Soslow, R.; Wang, T.L.; Shih Ie, M. TP53 mutations in serous tubal intraepithelial carcinoma and concurrent pelvic high-grade serous carcinoma-Evidence supporting the clonal relationship of the two lesions. J. Pathol. 2012, 226, 421-426. [CrossRef]

42. Alsner, J.; Jensen, V.; Kyndi, M.; Offersen, B.V.; Vu, P.; Borresen-Dale, A.L.; Overgaard, J. A comparison between p53 accumulation determined by immunohistochemistry and TP53 mutations as prognostic variables in tumours from breast cancer patients. Acta Oncol. 2008, 47, 600-607. [CrossRef]

43. Kim, J.Y.; Park, K.; Jung, H.H.; Lee, E.; Cho, E.Y.; Lee, K.H.; Bae, S.Y.; Lee, S.K.; Kim, S.W.; Lee, J.E.; et al. Association between Mutation and Expression of TP53 as a Potential Prognostic Marker of Triple-Negative Breast Cancer. Cancer Res. Treat. 2016, 48, 1338-1350. [CrossRef]

44. Cakir, A.; Isik Gonul, I.; Ekinci, O.; Cetin, B.; Benekli, M.; Uluoglu, O. GATA3 expression and its relationship with clinicopathological parameters in invasive breast carcinomas. Pathol. Res. Pr. 2017, 213, 227-234. [CrossRef]

45. Hisamatsu, Y.; Tokunaga, E.; Yamashita, N.; Akiyoshi, S.; Okada, S.; Nakashima, Y.; Taketani, K.; Aishima, S.; Oda, Y.; Morita, M.; et al. Impact of GATA-3 and FOXA1 expression in patients with hormone receptor-positive/HER2-negative breast cancer. Breast Cancer 2015, 22, 520-528. [CrossRef]

46. Ademuyiwa, F.O.; Thorat, M.A.; Jain, R.K.; Nakshatri, H.; Badve, S. Expression of Forkhead-box protein A1, a marker of luminal A type breast cancer, parallels low Oncotype DX 21-gene recurrence scores. Mod. Pathol. 2010, 23, 270-275. [CrossRef]

47. West, M.; Blanchette, C.; Dressman, H.; Huang, E.; Ishida, S.; Spang, R.; Zuzan, H.; Olson, J.A., Jr.; Marks, J.R.; Nevins, J.R. Predicting the clinical status of human breast cancer by using gene expression profiles. Proc. Natl. Acad. Sci. USA 2001, 98, 11462-11467. [CrossRef]

48. Jenssen, T.K.; Kuo, W.P.; Stokke, T.; Hovig, E. Associations between gene expressions in breast cancer and patient survival. Hum. Genet. 2002, 111, 411-420. [CrossRef]

49. Bertucci, F.; Houlgatte, R.; Benziane, A.; Granjeaud, S.; Adelaide, J.; Tagett, R.; Loriod, B.; Jacquemier, J.; Viens, P.; Jordan, B.; et al. Gene expression profiling of primary breast carcinomas using arrays of candidate genes. Hum. Mol. Genet. 2000, 9, $2981-2991$. [CrossRef] [PubMed]

50. Ciocca, V.; Daskalakis, C.; Ciocca, R.M.; Ruiz-Orrico, A.; Palazzo, J.P. The significance of GATA3 expression in breast cancer: A 10-year follow-up study. Hum. Pathol. 2009, 40, 489-495. [CrossRef]

51. Perou, C.M.; Sorlie, T.; Eisen, M.B.; van de Rijn, M.; Jeffrey, S.S.; Rees, C.A.; Pollack, J.R.; Ross, D.T.; Johnsen, H.; Akslen, L.A.; et al. Molecular portraits of human breast tumours. Nature 2000, 406, 747-752. [CrossRef] [PubMed]

52. Langerod, A.; Zhao, H.; Borgan, O.; Nesland, J.M.; Bukholm, I.R.; Ikdahl, T.; Karesen, R.; Borresen-Dale, A.L.; Jeffrey, S.S. TP53 mutation status and gene expression profiles are powerful prognostic markers of breast cancer. Breast Cancer Res. 2007, 9, R30. [CrossRef] 
53. McCleskey, B.C.; Penedo, T.L.; Zhang, K.; Hameed, O.; Siegal, G.P.; Wei, S. GATA3 expression in advanced breast cancer: Prognostic value and organ-specific relapse. Am. J. Clin. Pathol. 2015, 144, 756-763. [CrossRef]

54. Chen, Y.; Chen, C.; Yang, B.; Xu, Q.; Wu, F.; Liu, F.; Ye, X.; Meng, X.; Mougin, B.; Liu, G.; et al. Estrogen receptor-related genes as an important panel of predictors for breast cancer response to neoadjuvant chemotherapy. Cancer Lett. 2011, 302, 63-68. [CrossRef]

55. Tominaga, N.; Naoi, Y.; Shimazu, K.; Nakayama, T.; Maruyama, N.; Shimomura, A.; Kim, S.J.; Tamaki, Y.; Noguchi, S. Clinicopathological analysis of GATA3-positive breast cancers with special reference to response to neoadjuvant chemotherapy. Ann. Oncol. 2012, 23, 3051-3057. [CrossRef]

56. Guo, Y.; Yu, P.; Liu, Z.; Maimaiti, Y.; Chen, C.; Zhang, Y.; Yin, X.; Wang, S.; Liu, C.; Huang, T. Prognostic and clinicopathological value of GATA binding protein 3 in breast cancer: A systematic review and meta-analysis. PLoS ONE 2017, 12, e0174843. [CrossRef] [PubMed]

57. Andre, F.; Ismaila, N.; Henry, N.L.; Somerfield, M.R.; Bast, R.C.; Barlow, W.; Collyar, D.E.; Hammond, M.E.; Kuderer, N.M.; Liu, M.C.; et al. Use of Biomarkers to Guide Decisions on Adjuvant Systemic Therapy for Women With Early-Stage Invasive Breast Cancer: ASCO Clinical Practice Guideline Update-Integration of Results From TAILORx. J. Clin. Oncol. 2019, 37, 1956-1964. [CrossRef] [PubMed]

58. Harris, L.N.; Ismaila, N.; McShane, L.M.; Andre, F.; Collyar, D.E.; Gonzalez-Angulo, A.M.; Hammond, E.H.; Kuderer, N.M.; Liu, M.C.; Mennel, R.G.; et al. Use of Biomarkers to Guide Decisions on Adjuvant Systemic Therapy for Women With Early-Stage Invasive Breast Cancer: American Society of Clinical Oncology Clinical Practice Guideline. J. Clin. Oncol. 2016, 34, 1134-1150. [CrossRef]

59. Krop, I.; Ismaila, N.; Andre, F.; Bast, R.C.; Barlow, W.; Collyar, D.E.; Hammond, M.E.; Kuderer, N.M.; Liu, M.C.; Mennel, R.G.; et al. Use of Biomarkers to Guide Decisions on Adjuvant Systemic Therapy for Women With Early-Stage Invasive Breast Cancer: American Society of Clinical Oncology Clinical Practice Guideline Focused Update. J. Clin. Oncol. 2017, 35, 2838-2847. [CrossRef] 